\title{
RELATIONSHIP BETWEEN PUPILLARY SIZE, BRIGHTNESS AND PHOTORECEPTOR RESPONSES FOR UNRELATED SELF-LUMINOUS STIMULI AT LOW PHOTOPIC LIGHT LEVELS
}

\author{
Sandoval Salinas C. ${ }^{1}$; Hermans S. ${ }^{2}$; Sandoval J. ${ }^{1}$; Smet K.A.G. ${ }^{2}$; Hanselaer P. ${ }^{2}$; Colombo E. ${ }^{1}$ \\ ${ }^{1}$ Department of Lighting, Light and Vision, "Ing.HCBühler" (FACET-UNT), Tucumán, Argentina \\ ${ }^{2}$ KU Leuven, ESAT/Light\&Lighting Laboratory, Ghent, BELGIUM
}

\begin{abstract}
A research on the correlation between the initial pupillary light reflex, the perceptual brightness and the excitations of the photoreceptors was performed for unrelated self-luminous $10^{\circ}$ stimuli at low photopic light levels $\left(5\right.$ to $\left.80 \mathrm{~cd} / \mathrm{m}^{2}\right)$. All stimuli were optically characterized using a spectroradiometer. For determining the pupillary diameter an Eye Tracker was used. The perceived brightness was evaluated with the magnitude estimation method. Test stimuli were presented alternating with a reference stimulus and the Michelson contrast of the pupillary diameter between test and reference conditions was calculated. It was found that the coefficient of determination between the pupillary response and the perceived stimulus brightness was higger than the corresponding value for luminance, allowing the suggestion that brightness has a greater effect on pupillary size than luminance. Nevertheless, this is not the complete story: highly saturated red and blue stimuli both induce a high brightness perception but the pupil contraction induced by the blue stimuli is much higher than for the red stimuli. Pupillary diameter was also studied as a function of the relative excitations of the five photoreceptors. The effect of rod and ipRGC excitations on pupillary size variation seems to be larger than that of the other photoreceptors. However, for the working conditions prevailing in this research, it could be expected that rods are not very active and that the ipRGC response might be the major driving mechanism.
\end{abstract}

Keywords: unrelated self-luminous stimuli; pupillary size; brightness; photoreceptors

\section{INTRODUCTION}

A typical visual scene is characterized by a wide spatial dynamic range with respect to luminance. Furthermore, when observing and exploring a visual scene, quick eye movements or saccades take place during which retinal neurons have to deal with a temporally high range of retinal irradiances. Although the dynamic range of the retinal photoreceptors as such is limited, adaptation mechanisms allow for distinguishing objects in a shadow while avoiding saturation from the sky. The pupil can be considered as the aperture stop of the eye; both the quality and irradiance of the retinal image are affected by changes in the pupillary diameter. The pupil plays a role as one of the gain control systems in the visual pathway ${ }^{1}$ because it modulates retinal illumination. The change of the pupillary size represents one step in the whole adaptation process. Once the light passed through the pupil, two essentially mutually exclusive retinal adaptive mechanisms that automatically adjust sensitivity in the intervals between saccades have been identified ${ }^{2}$. One mechanism is within the cone photoreceptors themselves and the other occurs as signals are relayed from cone bipolar cells to ganglion cells. As luminance levels increase, the main site of adaptation switches from the bipolar to ganglion circuitry.

The pupillary light reflex induces a contraction of the pupil when ambient luminance is high, and this causes the amount of retinal illumination to be reduced. The aperture enlarges when light intensity is low, and more light is allowed to the retina. The pupillary diameter for a human eye ranges between about $2 \mathrm{~mm}$ and $8 \mathrm{~mm}$. These pupillary responses are controlled by a neural subcortical network able to rapidly react to changes in light; the pupil responds to changes in room illumination even when the visual cortex is completely damaged or all conscious visual perception has been lost ${ }^{3}$. The parasympathetic nervous system is the main system responsible for constriction of the pupil in response to light. The signal is transmitted along the axons of the retinal ganglion cells (RGC). At the end of the optic tract, the axons of the RGCs responsible for the pupillary light reflex separate from the visual axons and transport the signal to synapses in the pretectal olive nucleus ${ }^{4}$. Narrowing of the pupil following each fixation during saccadic eye movements increases the depth of focus and insures image clarity ${ }^{5,6}$. Various equations have been proposed in an attempt to predict the pupillary diameter ${ }^{7,8}$. All these equations use the luminance of the scenery as input, and some of them also require the area of 
the stimulus. Not only changes in luminance will cause a pupillary light reflex; also changes in chromaticity and spectral content of the retinal image will cause a pupillary reaction ${ }^{6,9,10}$.

Nowadays it is understood that the pupillary light response is mediated by five photoreceptors ${ }^{11}$ : the retinal L-cones, $\mathrm{M}$ cones, S-cones and rods (all having light sensitive, opsin-based pigments), and the intrinsically photosensitive retinal ganglion cells (ipRGCs) that contain a light sensitive pigment called melanopsin and whose axons do not relay in the lateral geniculate bodies, but pass to a midbrain region (the pretectum) that controls reflex constriction and dilation of the pupil ${ }^{1}$. The L-cone, M-cone and S-cone spectral sensitivities are maximal at $580 \mathrm{~nm}, 540 \mathrm{~nm}$ and $440 \mathrm{~nm}$, respectively. The rod spectral sensitivity is maximal at $498 \mathrm{~nm}$ while the melanopsin spectral sensitivity is maximal at $480 \mathrm{~nm}^{12}$.

In describing the role of these five photoreceptors, two parallel visual systems must be considered: an image-forming visual system and a non-image-forming visual system. In the first one, visual signals originating in rods and cones are transmitted to the brain through retinal ganglion cells (RGCs); this system interprets and tracks visual objects and patterns through its projections to the lateral geniculate nucleus and the midbrain. The second visual system, the nonimage-forming one, that has melanopsin as the mainly responsible photopigment, drives photic responses such as circadian rhythms, control of pupillary size, melatonin release, and others ${ }^{13}$.

Melanopsin-containing cells receive rod and cone inputs in addition to their intrinsic photosignal. Yet, a sustained pupillary constriction can be produced by light striking the retinal ganglion cells itself, and by inputs from cones and rods received by the same ganglion cells $5,6,14,15$. It has been stressed that the pupillary light reflex and other non-visual light responses are abolished if rod-cone and melanopsin signaling pathways are disrupted simultaneously or if melanopsin cells are selectively killed ${ }^{15,16}$. Melanopsin cells appear not to be required for pattern-forming vision, even though in 2005 Dacey et al ${ }^{17}$ suggested that conscious visual perception might be influenced by melanopsin-based signal in diurnal trichromatic primates, for whom they had found a merge between non-image-forming and image-forming retinal pathways. Melanopsin seems to be necessary for triggering the pupillary light reflex. Although it is difficult to investigate how signals from the classical photoreceptors and ipRGCs act in humans, some results have been obtained.

The behavioral dynamics of the pupillary light reflex has been characterized by an initial transient constriction at light onsets, and a posterior sustained larger pupil for as long as the light stimulus remains ${ }^{10}$.

In 2006, Tsujimura et al. ${ }^{1}$ found that for a bright steady background, the pupillary diameter change induced by ipRGCs was larger than that induced by the $L$ and $M$ cone signals. While it was initially assumed that the transient portion of the pupillary light reflex was driven exclusively by rods or cones and the sustained portion was driven solely by the melanopsin photo-response at photopic irradiance ${ }^{13}$, more recent studies show that outer retinal photoreceptors also contribute to sustained firing during long duration light stimuli ${ }^{9}$. In 2012 , Gooley et al. ${ }^{15}$ showed that melanopsin is the primary photopigment that drives sustained pupillary constriction in response to high-irradiance light. Rod-cone photoreceptors mediate rapid constriction of the pupil following light stimulus onset and allow the pupil to track highfrequency intermittent light stimuli. During exposure to continuous light, the relative contribution of cone photoreceptors to pupillary constriction decreases over time.

Pupil response is mediated not only by irradiance-coding processes but also by wavelength ${ }^{5}$. Both achromatic and chromatic signals drive the pupil responses (a chromatic stimulus gives rise to a perceived colour possessing hue, while an achromatic stimulus gives rise to a perceived colour devoid of hue ${ }^{18}$ ). The contribution of the chromatic signal is larger than the contribution of the achromatic signal: a smaller stimulus contrast for chromatic stimuli will induce an equal pupillary response than a larger contrast of achromatic stimuli ${ }^{1}$.

Pupillary light reflex is most sensitive to blue light ${ }^{15}$. In normal eyes and at low luminance values $\left(1 \mathrm{~cd} / \mathrm{m}^{2}\right)$, blue light evoked much greater pupil responses compared with red light when matched for photopic luminance. The transient pupil contraction was generally larger than the sustained contraction, and this disparity was greatest at the lowest light intensity and least apparent when intense $\left(100 \mathrm{~cd} / \mathrm{m}^{2}\right)$ blue light was presented ${ }^{19}$. In addition, the pupillary contraction is faster for blue and red light than for green and yellow light ${ }^{20}$. 
Brightness is one of the absolute attributes of the visual sensation according to which an area appears to emit more or less light ${ }^{21}$. While the dependence of the pupillary diameter with luminance has been extensively investigated ${ }^{22,23,24,25}$, and relationship equations have been proposed between these variables ${ }^{8}$, this is not the case for the dependence of the pupillary diameter with brightness, a relationship that has been little studied so far. The physiological substrate of the brightness perception is not well understood ${ }^{26}$. In most Colour Appearance Models (CAM), brightness is modelled as a function of the adapted cone responses. In some cases, it contains two contributions: an achromatic contribution and a contribution modelling the so-called Helmholtz-Kohlrausch $(\mathrm{H}-\mathrm{K})$ effect ${ }^{27}$. The $\mathrm{H}-\mathrm{K}$ effect deals with the effect of colorfulness (attribute of a visual sensation according to which the perceived color of an area appears to be more or less chromatic) or saturation (colorfulness of an area judged in proportion to its brightness) on perceived brightness ${ }^{21,28}$. According to the $\mathrm{H}-\mathrm{K}$ effect, the brightness of two stimuli with the same luminance changes in accordance with their saturation: higher saturated colors appear brighter than lower saturated ones ${ }^{21,28,29,30}$. It was also shown that ipRGCs contribute to perceived brightness, with greater perceived brightness for increased melanopsin excitation ${ }^{31}$. Regarding to pupillary light reflex, perceived brightness is clearly a higher order quantity than luminance because it involves physiological, psychological, and neurological-based factors ${ }^{32,33,34,35,36,37,38}$ while luminance is a photometric quantity.

In this paper, the direct correlation between the initial pupillary light reflex and the perceived brightness (including the $\mathrm{H}-\mathrm{K}$ effect), as well as the correlation of this pupillary light reflex with the excitations of the photoreceptors, are investigated for unrelated self-luminous $10^{\circ}$ stimuli of 5 different hues and luminance levels between 5 and $80 \mathrm{~cd} / \mathrm{m}^{2}$. Unrelated stimuli are stimuli perceived in isolation from any other stimulus, which occurs when the stimuli are surrounded by a dark background.

\section{EXPERIMENTAL SYSTEM AND METHODOLOGY}

Pupillary diameter measurements and the perceived brightness data were gathered for different observers using a variety of stimuli with different hues and luminance values. The study protocols followed the tenets of the Declaration of Helsinki.

2.1. EXPERIMENTAL SETUP. A specially designed experimental room has been set up. The walls are covered by black curtains; the floor and ceiling are painted black. A self-luminous wall was built by illuminating a large diffuser from the rear by a BenQ MS630ST projector (figure 1.a). The projector allows generating a variety of stimuli and surroundings, with variable shape, size, chromaticity and luminance. In this study, a circular stimulus of $10^{\circ}$ size is projected on the center of the screen, while its background is kept dark in order to generate unrelated stimuli.

The projector was the only light source present in the room while the measurements were made. To make sure that the background is completely dark, the projector was placed inside a closed black box in which a diaphragm allowed light to pass towards the screen. A control measurement was performed; the luminance of the background of the stimulus was only $3.2610^{-2} \mathrm{~cd} / \mathrm{m}^{2}$ with a spatial inhomogeneity less than $20 \%$.

The observations are made from the front side, where participants put their heads in an ophthalmologic support to keep them fixed at a distance of $150 \mathrm{~cm}$ from the screen (Figure 1.b).
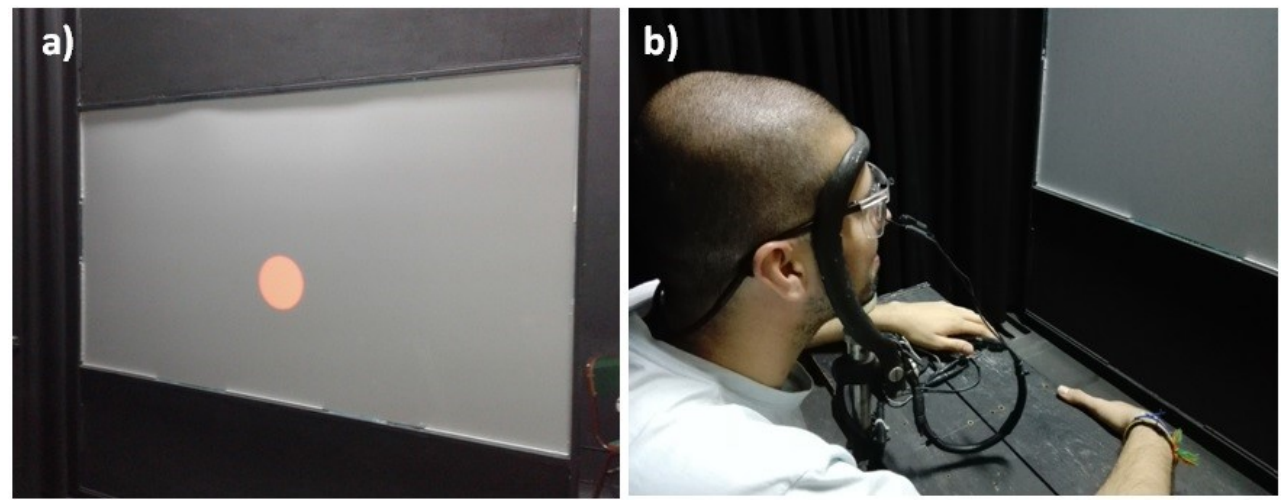

Figure 1. a) Self-luminous wall used to present the stimuli and b) observer sitting in front of the screen, both photos taken with room light on. 
2.2. STIMULI. Thirty $10^{\circ}$ test stimuli of five different hues (white, blue, red, green and yellow) at six luminance values (5, $10,20,30,50$ and $80 \mathrm{~cd} / \mathrm{m}^{2}$ ) have been used. They are designated by the first character of the hue followed by the luminance; e.g. $\mathrm{G} 50$ represents the green stimulus with a $50 \mathrm{~cd} / \mathrm{m}^{2}$ luminance. All luminance values were calculated using the standard spectral luminous efficiency function $V_{10}(\lambda)$ for the $\mathrm{CIE} 196410^{\circ}$ observer $^{39}$. Luminance is used to describe the intensity of the stimuli because it is a well-known and well established quantity and a lot of studies report on the relation between luminance and pupil diameter.

All the stimuli were presented to each observer randomly, organized into six separate experimental sessions of five stimuli each to avoid observer fatigue. A stimulus with CIE 1976 chromaticity coordinates $\left(u^{\prime}{ }_{10}, v^{\prime}{ }_{10}\right)=(0.209,0.476)$, compatible with equal-energy white (EEW), and $42.3 \mathrm{~cd} / \mathrm{m}^{2}$ luminance (the average value of the luminance values of all stimuli), was added to be used as reference in the magnitude estimation experiments ${ }^{40,411,42}$.

All stimuli were optically characterized using a PhotoResearch PR-715 Spectrascan spectroradiometer calibrated to measure spectral radiance. As an example, Figure 2 shows the spectral radiance of the stimuli with a $30 \mathrm{~cd} / \mathrm{m}^{2}$ luminance for all hues. The colors of the lines correspond to those of the stimuli except for white stimulus, which is represented in black.

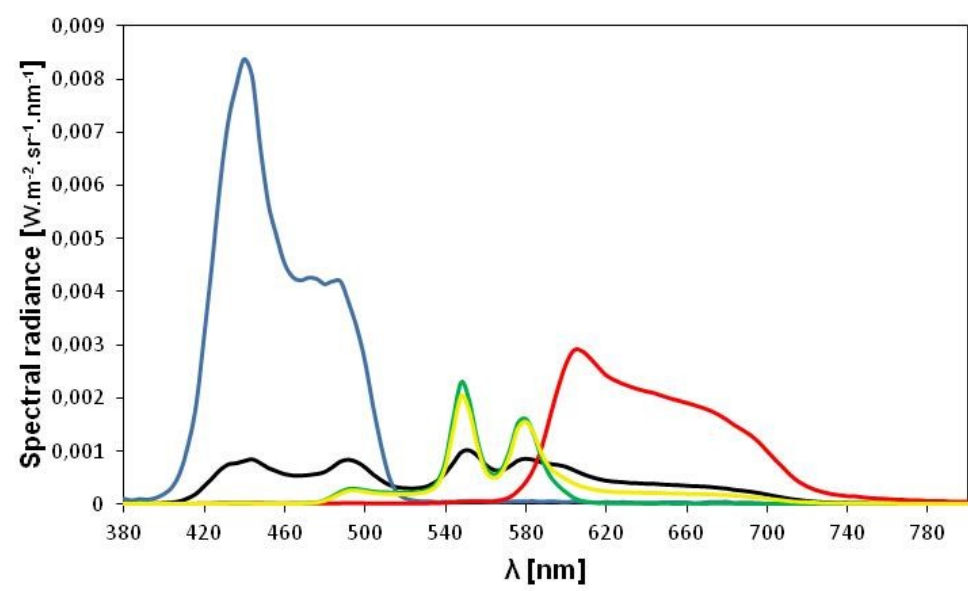

Figure 2. Spectral radiance from stimuli with a $30 \mathrm{~cd} / \mathrm{m}^{2}$ luminance.

A uniformity control showed that the spatial and temporal non-uniformities of each stimulus were less than $10 \%$. The average CIE $1976 u^{\prime} v^{\prime}$ chromaticity and standard deviation (SD) of the chromaticity of the stimuli for each hue over the luminance range are summarized in Table 1.

\begin{tabular}{|l|c|c|c|c|c|}
\cline { 2 - 6 } \multicolumn{1}{c|}{} & White & Blue & Red & Green & Yellow \\
\hline$\left({\overline{u^{\prime}}}_{10},{\overline{v^{\prime}}}_{10}\right)$ & $(0.208,0.475)$ & $(0.155,0.204)$ & $(0.430,0.533)$ & $(0.190,0.563)$ & $(0.218,0.561)$ \\
\hline$\left(S D_{u_{u}^{\prime}}, S D_{v_{w}^{\prime}}\right)$ & $(0.003,0.003)$ & $(0.011,0.019)$ & $(0.009,0.001)$ & $(0.002,0.005)$ & $(0.001,0.001)$ \\
\hline
\end{tabular}

Table 1. Average and standard deviation for the CIE $1976 u^{\prime} v^{\prime}$ chromaticity for each hue.

All stimuli that share a given hue have approximately the same CIELUV saturation ${ }^{43}$, Su'v'. The average saturation values, together with their standard deviation (SD), are shown in table 2. Blue stimuli have the highest saturation, followed in decreasing order by red, green and yellow ones.

\begin{tabular}{|l|c|c|c|c|c|}
\cline { 2 - 6 } \multicolumn{1}{c|}{} & White & Blue & Red & Green & Yellow \\
\hline${\text { S } \text { u'v }^{\prime}}^{n} D_{\text {su'v }^{\prime}}$ & 0.05 & 3.6 & 3.0 & 1.16 & 1.11 \\
\hline
\end{tabular}

Table 2. Average and standard deviation for the CIELUV saturation for each hue.

2.3. OBSERVERS. Six observers (three female and three male) participated, with ages between 30 and 39 years (with an average of 34.5 years). All observers were naive with respect to the purpose of the experiment. All of them passed the Ishihara 24 plate test to verify if they have normal colour vision. Before each measurement session, each observer was interviewed to verify that he/she had not consumed any substance or was going through any emotional circumstance 
that could modify his/her pupillary reflex or performance on tasks. Understanding and written consent were obtained for each observer prior to the start of the study.

\subsection{EXPERIMENTAL PROCEDURE}

2.4.1 Experimental sequence. The pupillary diameter and the perceived brightness were determined by each observer, for all stimuli, in the six experimental sessions. For measuring the pupillary diameter, an Arrington Research eye tracker ${ }^{44}$ was used. The perceived brightness was evaluated using the magnitude estimation method ${ }^{40,41,42}$.

At the beginning of each experimental session, the observers were sitting in the dark for 5 minutes in order to be fully dark adapted when starting the experiments. In each experimental session, each observer performed two runs of measurements. In the first run, the observer was asked to fixate his or her gaze in the center of the circular stimulus and the pupillary size corresponding to each stimulus was measured with the eye tracker. This first run also allowed the observer to know all the stimuli whose brightness was to be evaluated in the next run. In the second run, without the eye tracker, each observer had to evaluate the brightness of each stimulus in relation to that of the reference stimulus. For controlling the intra-observer variability, six of the thirty test stimuli were presented twice (B20, R20, G20, Y20, W20 and W80).

In each run, first a reference stimulus was shown for 20 seconds, then a test stimulus was presented for 15 seconds followed by the same reference stimulus, and so on. At the beginning of each experimental session, the instructions shown in the Appendix were given to each observer.

The stimuli experimental sequence is represented in Figure 3.

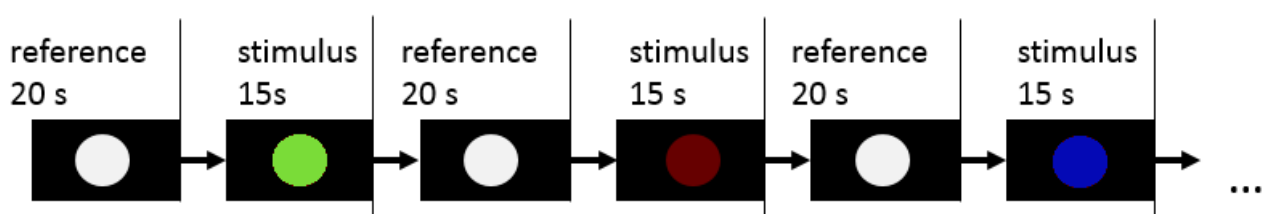

Figure 3. Schematic view of the test and reference stimuli presentation sequence.

2.4.2. Pupillary size measurements. The pupil was tracked by using the dark pupil eye tracking method ${ }^{44}$. An infrared light source illuminated the eye while an infrared camera recorded the image of the eye. Both were connected to a frame of glasses (Figure 4.a), in front of the right eye of the observer. The infrared LED serves to illuminate the eye and to provide a specular reflection from the cornea and iris. The pupil acts as an infrared sink that appears as a black hole (Figure 4.b). The video signal from the camera is digitized by the video capture device using ViewPoint EyeTracker software, controlled from MATLAB. The eye tracker continuously measures the size of the pupil of each observer with a frame rate of $30 \mathrm{fps}$. The software continuously calculates the relative size of the pupil by fitting an ellipse to the darkened pupil. The long axis of this ellipse under a specific viewing angle of the camera corresponds to the pupil diameter. To avoid spurious ellipses adjustment during blinking a median filter was used.

In each experimental session, the pupillary size was measured for about 10 seconds in total darkness (during the preliminary adaptation period) and during the alternating projections of the reference stimulus and the coloured stimuli.

The infrared illuminator and camera systems provided by Arrington Research Inc. were designed to be well within safe limits of exposure of the eye ${ }^{44}$.
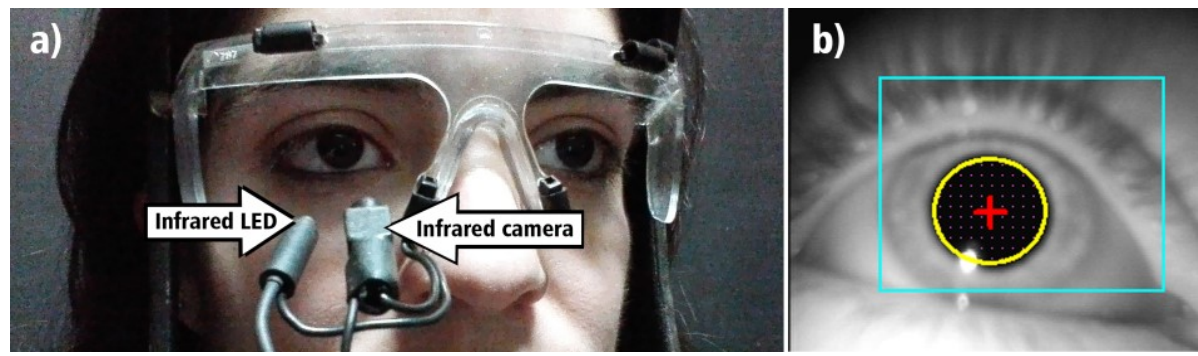
Figure 4. a) Head mounted device (infrared LED and camera) in daylight conditions.

b) Infrared image of the eye with a dark pupil and a fitted ellipse.

During the reference and test stimulus period, two specific arithmetic mean pupillary diameters can be obtained (Figure 5): the OFF-sustained diameter Doff and the ON-transient diameter DoN ${ }^{6}$. Doff corresponds to the mean value obtained between $18.5 \mathrm{~s}-19.5 \mathrm{~s}$ after reference stimulus onset (the last $500 \mathrm{~ms}$ of the reference stimulus presentation are discarded because of the anticipatory effect generated by repeated tests ${ }^{45}$ ). Don corresponds to the mean value between $0.5 \mathrm{~s}-1.5 \mathrm{~s}$ after test stimulus onset (the first $500 \mathrm{~ms}$ of the test stimulus presentation are also not considered because of the pupil's response time to a light stimulus ${ }^{46}$ ). These two values allow the calculation of the initial pupillary light reflex for each stimulus.

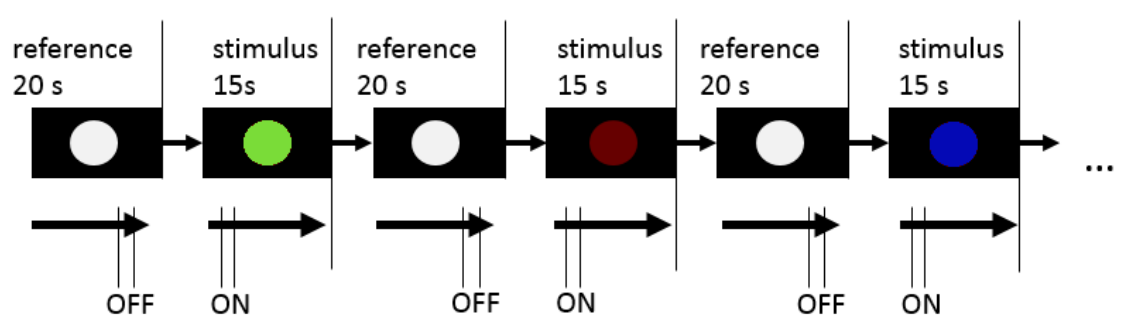

Figure 5. Temporal sequence of OFF-sustained diameter and ON-transient diameter.

2.4.3. Brightness measurements. The perceived brightness of the self-luminous stimuli was evaluated using the magnitude estimation method, in which each observer is asked to quantify, on a half-open scale, how bright he or she perceives the presented test stimulus in comparison to the W42.3 equal-energy white reference stimulus, which had the pre-assigned brightness of 50 to guide the observer. The perceived brightness values could range from 0 , representing a dark stimulus, to any other positive value without defining an upper limit. The results of this method are numerical and scalable data for the observed brightness ${ }^{27,42}$.

Stimuli presentation was organized in accordance with earlier experiments on brightness perception of unrelated stimuli $^{47}$. The test stimuli were presented in alternation with the reference stimulus $(20 \mathrm{~s}$ reference stimulus, $15 \mathrm{~s}$ test stimulus; Figure 5). Observers had to assess the brightness of test stimuli, in relation to the reference stimulus, immediately after each test stimulus disappeared and the reference stimulus re-appeared.

2.4.4. Photoreceptors excitations calculation. The excitations of the five photoreceptors were calculated for each stimulus (Equation 1). In 2006, the CIE provided ${ }^{48}$ a set of cone fundamentals, $\bar{l}_{10}(\lambda), \bar{m}_{10}(\lambda)$ and $\bar{s}_{10}(\lambda)$, specifically suited to stimuli with an angular extend of $10^{\circ}$. These cone fundamentals have been used to calculate the cone excitations $\rho$ (long wavelength), $\gamma$ (medium wavelength) and $B$ (short wavelength), of the stimuli. In 1951 , the CIE provided ${ }^{49}$ a sensitivity curve for rod signals, the CIE scotopic luminosity function $V^{\prime}(\lambda)$, which has been used to calculate the rod excitations. The ipRGC sensitivity function provided by Dacey et al. ${ }^{17}$ and Gamlin et al. ${ }^{50}$ has been used to calculate the ipRGC excitations.

The normalization constants have been chosen in such a way that the cone, rod and ipRGC excitations of spectral equalenergy white are identical and nominally equal to the CIE $200610^{\circ}$ luminance value. Note that the values of these excitations should not be considered as absolute excitations; they only reflect the weighted and integrated spectral sensitivity.

$$
\begin{aligned}
& \rho=676.7 \int_{390}^{830} L_{e, \lambda}(\lambda) \bar{l}_{10}(\lambda) d \lambda \\
& \gamma=794.0 \int_{390}^{830} L_{e, \lambda}(\lambda) \bar{m}_{10}(\lambda) d \lambda \\
& \beta=1461.5 \int_{390}^{830} L_{e, \lambda}(\lambda) \bar{s}_{10}(\lambda) d \lambda
\end{aligned}
$$




$$
\begin{aligned}
& \operatorname{rod}=833.8 \int_{390}^{830} L_{e, \lambda}(\lambda) V^{\prime}(\lambda) d \lambda \\
& i p R G C=928.6 \int_{390}^{830} L_{e, \lambda}(\lambda) \overline{i p R G C}(\lambda) d \lambda
\end{aligned}
$$

\subsection{DATA HANDLING}

The absolute pupillary diameter $D$ as measured by the eye tracker has not been used as such. It is known that $D$ values are smaller for older people ${ }^{51}$ and that $D$ values are higher or lower-compared to emmetropic populations- according to diverse refractive errors ${ }^{52}$. In order to avoid errors due to variations in visual refractive errors for any observer and to suppress errors due to variations in the distance between the iris and the camera, which also scales the measured $D$ values, a dimensionless "Michelson contrast" 53 pupillary diameter $D_{M C}$ has been used:

$$
D_{M C}=\frac{D_{O N}-D_{O F F}}{D_{O N}+D_{O F F}}
$$

with $D_{\text {ON }}$ and $D_{\text {OFF }}$ calculated as explained before. $D_{M C}$ was calculated for each observer and for each stimulus. The arithmetic mean and standard deviation for each stimulus over all observers were also determined. KolmogorovSmirnov tests and Shapiro-Wilk tests were performed to confirm that all $D_{M C}$ values are Gaussian distributed for all observers, justifying the use of the arithmetic mean over all observers per stimulus ${ }^{54}$. All the $D_{M c}$ error bars shown in this paper are calculated as standard errors.

For the brightness data handling, an average value of brightness $\left(Q_{a v g}\right)$ was obtained for each stimulus, by calculating the geometric mean of the data provided by all the observers for each stimulus ${ }^{55}$.

In symmetry with the definition of the $D_{M C}$ variable associated with the pupillary diameter, we have defined the Michelson contrast brightness $Q_{M C}$ and Michelson contrast luminance $L_{M C}$ variables, associated with the brightness and the luminance of the stimuli, respectively:

$$
Q_{M C}=\frac{Q_{S T I M}-Q_{R E F}}{Q_{S T I M}+Q_{R E F}}, \quad L_{M C}=\frac{L_{S T I M}-L_{R E F}}{L_{S T I M}+L_{R E F}}
$$

Analogously, the Michelson contrast excitations $\rho_{M C}, \gamma_{M C}, B_{M C}, \operatorname{rod}_{M C}$ and $i p R G C_{M C}$ for each stimulus were calculated:

$$
\begin{gathered}
\rho_{M C}=\frac{\rho_{O N}-\rho_{O F F}}{\rho_{O N}+\rho_{O F F}}, \quad \gamma_{M C}=\frac{\gamma_{O N}-\gamma_{O F F}}{\gamma_{O N}+\gamma_{O F F}}, \quad \beta_{M C}=\frac{\beta_{O N}-\beta_{O F F}}{\beta_{O N}+\beta_{O F F}} \\
\operatorname{rod}_{M C}=\frac{\operatorname{rod}_{O N}-\operatorname{rod}_{O F F}}{\operatorname{rod}_{O N}+\operatorname{rod}_{O F F}}, \quad i p R G C_{M C}=\frac{i p R G C_{O N}-i p R G C_{O F F}}{i p R G C_{O N}+i p R G C_{O F F}}
\end{gathered}
$$

The standardized residual sum of squares (STRESS) can be used to analyze the goodness of fit between two sets of data ${ }^{56}$; if two sets have a perfect agreement, the STRESS value will be zero.

Inter-observer variability for each stimulus, a measure for how consistent an observer is with respect to all other observers when measuring the same stimuli, was evaluated by calculating the STRESS value between the individual and the average observer. Intra-observer variability for each observer, a measure for how consistent an observer is with him- or herself, can be calculated with the same metric by comparing the results of one observer assessing the same stimulus twice. Mean inter- and intra- observer variabilities were determined by calculating the arithmetic mean of the corresponding STRESS values.

\section{RESULTS AND DISSCUSION}

\subsection{Pupillary diameter}


In Figure 6 a qualitative typical raw data of the variation of the pupillary size in time is shown. It is clear that with respect to the reference stimulus, pupillary contraction (e.g. when showing B80) and pupillary dilatations (Y10) do occur. It is also clear that the absolute pupillary diameter when presenting the reference is not always identical and stable. By calculating the Michelson contrast pupillary diameter $D_{M C}$, results become more robust.

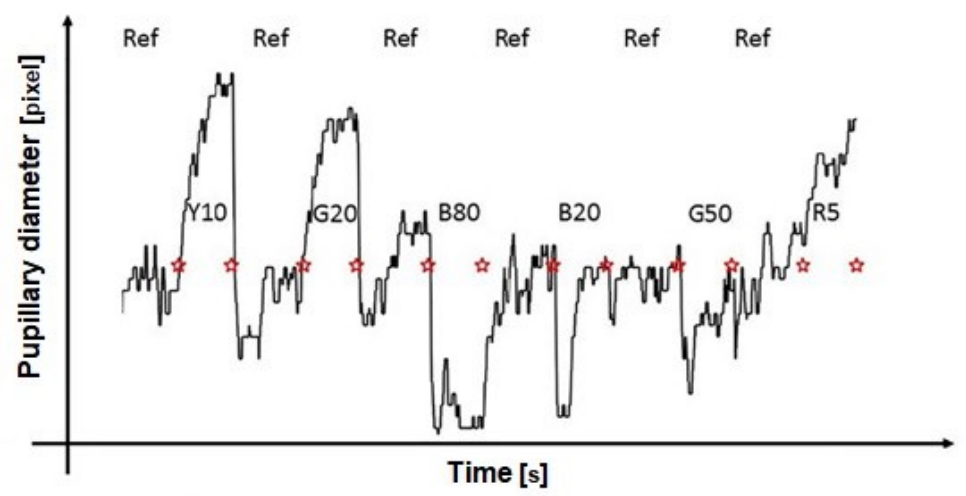

Figure 6. Measured pupillary diameter for one observer as a function of time.

The red stars indicate the switch from reference to test stimulus and vice versa.

It should be borne in mind that this type of recording, with so many fluctuations during the time of presentation of each stimulus, is usual in quasi-continuous measurements of the pupillary diameter ${ }^{45}$. Regarding these fluctuations, several authors who have reported similar high variability, have proposed explanations based on emotional and cognitive processes $^{57}$ and neuronal factors ${ }^{58}$. The very short fluctuations of pupillary diameter have been characterized as pupillary noise ${ }^{59}$, spontaneous pupillary oscillations ${ }^{60}$ and pupillary unrest ${ }^{61,62}$. In some studies, they have been related to variability in the firing patterns of brainstem neurons that control pupillary diameter ${ }^{61,62}$.

Regarding the differences shown by the average pupillary diameter obtained for successive presentations of the same stimulus to an observer, it should be taken into account that the pupillary diameter also responds to cognitive processes $^{63,64}$ and emotional processes ${ }^{65}$ developed by the observer. The value of $D$ might change due to stimulation through, for example, pleasant or unpleasant sounds or smells interfering during the development of the experiment or, even more, if the observer would have imagined scenes associated with pleasant or unpleasant events ${ }^{66}$. Recently, it has been suggested ${ }^{58}$, with consistent experimental evidence, that the activation of the locus coeruleus also impacts the pupillary diameter.

In conclusion, an accurate and reproducible determination of pupillary diameter is not straightforward, and significant values of intra-observer stress can be expected. The average inter-observer and intra-observer stress values for $D_{M C}$ are 0.30 and 0.47 , respectively. These stress values are compatible with values reported in literature, including the large value obtained for the intra-observer variation ${ }^{67}$.

The numerical values of the average Michelson contrast pupillary diameter $D_{M C}$ for each stimulus are presented in Table 3.

\begin{tabular}{|l|c|c|c|c|c|c|}
\cline { 2 - 7 } \multicolumn{1}{c|}{} & $\mathbf{5} \mathbf{c d} / \mathbf{m}^{\mathbf{2}}$ & $\mathbf{1 0} \mathbf{c d} / \mathbf{m}^{\mathbf{2}}$ & $\mathbf{2 0} \mathbf{c d} / \mathbf{m}^{\mathbf{2}}$ & $\mathbf{3 0} \mathbf{c d} / \mathbf{m}^{\mathbf{2}}$ & $\mathbf{5 0} \mathbf{c d} / \mathbf{m}^{\mathbf{2}}$ & $\mathbf{8 0} \mathbf{c d} / \mathbf{m}^{\mathbf{2}}$ \\
\hline Red & 0.024 & -0.023 & -0.020 & -0.007 & -0.007 & -0.038 \\
\hline Green & 0.058 & 0.043 & 0.011 & -0.003 & -0.037 & -0.091 \\
\hline Blue & -0.054 & -0.117 & -0.122 & -0.112 & -0.187 & -0.137 \\
\hline Yellow & 0.026 & 0.020 & 0.012 & -0.022 & -0.036 & -0.099 \\
\hline White & 0.038 & 0.028 & 0.014 & -0.045 & -0.027 & -0.113 \\
\hline
\end{tabular}

Table 3. Average Michelson contrast pupillary diameter $D_{M C}$ value for each stimulus.

\subsection{Brightness}

The averaged perceived brightness data are shown in Table 4. The inter-observer and intra-observer stress values are 0.035 and 0.027 , respectively. 


\begin{tabular}{|l|c|c|c|c|c|c|}
\cline { 2 - 7 } \multicolumn{1}{c|}{} & $\mathbf{5} \mathbf{c d} / \mathbf{m}^{\mathbf{2}}$ & $\mathbf{1 0} \mathbf{c d} / \mathbf{m}^{\mathbf{2}}$ & $\mathbf{2 0} \mathbf{c d} / \mathbf{m}^{\mathbf{2}}$ & $\mathbf{3 0} \mathbf{c d} / \mathbf{m}^{\mathbf{2}}$ & $\mathbf{5 0} \mathbf{c d} / \mathbf{m}^{\mathbf{2}}$ & $\mathbf{8 0} \mathbf{c d} / \mathbf{m}^{\mathbf{2}}$ \\
\hline Red & 39 & 44 & 49 & 58 & 63 & 74 \\
\hline Green & 30 & 40 & 42 & 51 & 60 & 75 \\
\hline Blue & 46 & 45 & 61 & 69 & 78 & 86 \\
\hline Yellow & 23 & 36 & 42 & 48 & 57 & 69 \\
\hline White & 18 & 28 & 38 & 42 & 54 & 63 \\
\hline
\end{tabular}

Table 4. Averaged perceived brightness $Q_{a v g}$ for each stimulus.

In 2015, a colour appearance model CAM15u was published to predict the brightness (among other perceptual correlates) of circular unrelated self-luminous $10^{\circ}$ stimuli ${ }^{42}$. This model allows calculating the brightness $Q$ as the sum of an achromatic signal and a chromatic signal. Both contributions are calculated directly from the three cone responses using the $2006 \mathrm{ClE}$ cone fundamentals.

The values obtained for the average perceived brightness were compared with the values predicted by the CAM15u model for each stimulus, as shown in Figure 7. In this and the following figures, the colors of the circles correspond to those of the stimuli except for white stimuli that are represented in black, and error bars are the standard error of the geometric mean.

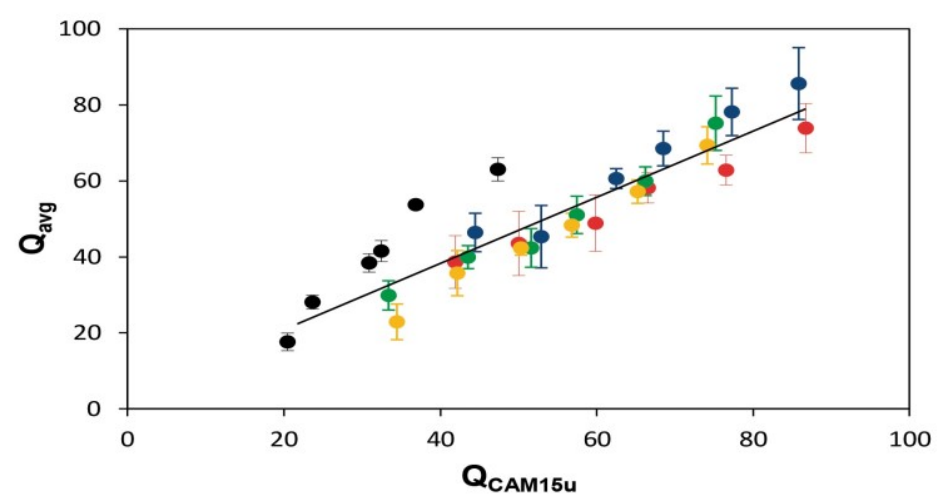

Figure 7. Perceived brightness of the average observer compared with the predicted brightness of the CAM15u model.

The correlation between the perceived and the predicted brightness data results in a coefficient of determination $\left(R^{2}\right)$ of 0.81, a Pearson correlation coefficient $\left(r_{p}\right)$ equal to 0.90 , and a Spearman rank correlation coefficient $\left(r_{s}\right)$ of 0.89 . Although the neutral stimuli are somewhat diverging from the coloured ones, the value obtained for $R^{2}$ shows that the brightness predicted by the CAM $15 \mathrm{u}$ model explains $81 \%$ of the variability of the average brightness perceived by observers. It can be concluded that the brightness values provided by the observers are quite well in line with the predictions of the CAM15u model, supporting the validity of the model.

\subsection{Brightness and luminance}

In Figure 8 , the average brightness $Q_{\text {avg }}$ is shown as a function of the luminance. 


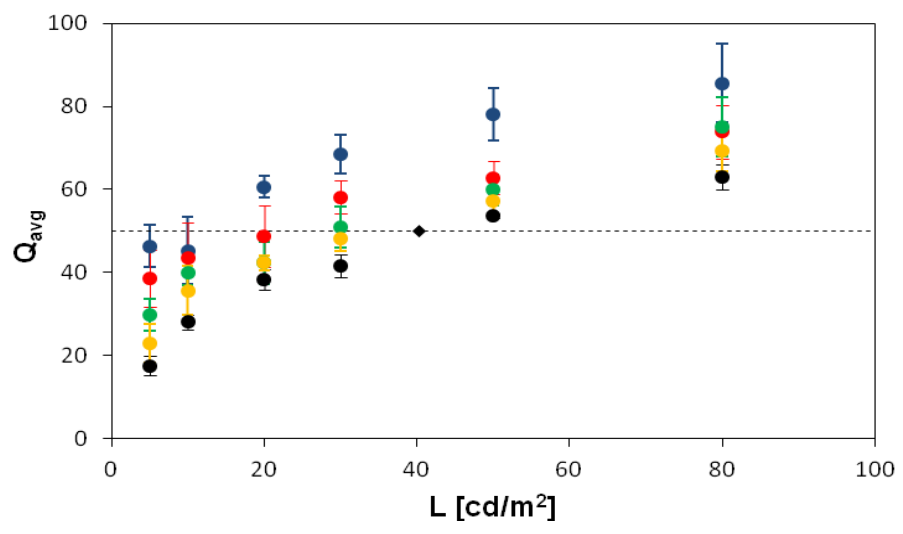

Figure 8. Averaged perceived brightness versus luminance for all stimuli for each hue.

As expected, brightness increases with luminance. Coloured stimuli having the same luminance as white stimuli are always observed brighter than the white ones; this result is clearly in line with the H-K effect. This effect is maximum for blue stimuli and minimum for yellow ones, in accordance with the saturation values mentioned in Table 2 .

The correlation between the perceived brightness and luminance data results in a coefficient of determination $\left(R^{2}\right)$ of 0.71 , a Pearson correlation coefficient $\left(r_{p}\right)$ equal to 0.84 , and a Spearman rank correlation coefficient $\left(r_{s}\right)$ of 0.85 .

\subsection{Average perceived brightness, predicted brightness and luminance}

The correlation between $L$ and $Q_{\text {CAM15u }}$ with $Q_{\text {avg }}$ has been statistically analyzed.

The statistical significance of the difference in the two Pearson correlation coefficients was checked using the method for overlapping correlated correlation coefficients proposed by Meng et al. ${ }^{68}$. No significant difference $(p=0.21)$ could be detected between the correlations, indicating that $L\left(r_{p}=0.84\right)$ and $Q_{\text {CAM15u }}\left(r_{p}=0.90\right)$ have the same predictive power for $Q_{a v g}$ for the data in the current study. However, from Fig. 7, it is clear that the "white" stimuli deviate from the rest of the stimuli. When the white stimuli are removed, $Q_{\text {CAM15u }}\left(r_{p}=0.96\right)$ is a significantly better predictor than the luminance $L\left(r_{p}=0.87\right)$.

\subsection{Pupillary diameter and luminance}

In Figure 9 the Michelson contrast pupillary diameter $D_{M C}$ is shown for all stimuli as a function of luminance $L$ and Michelson contrast luminance $L_{M C}$.
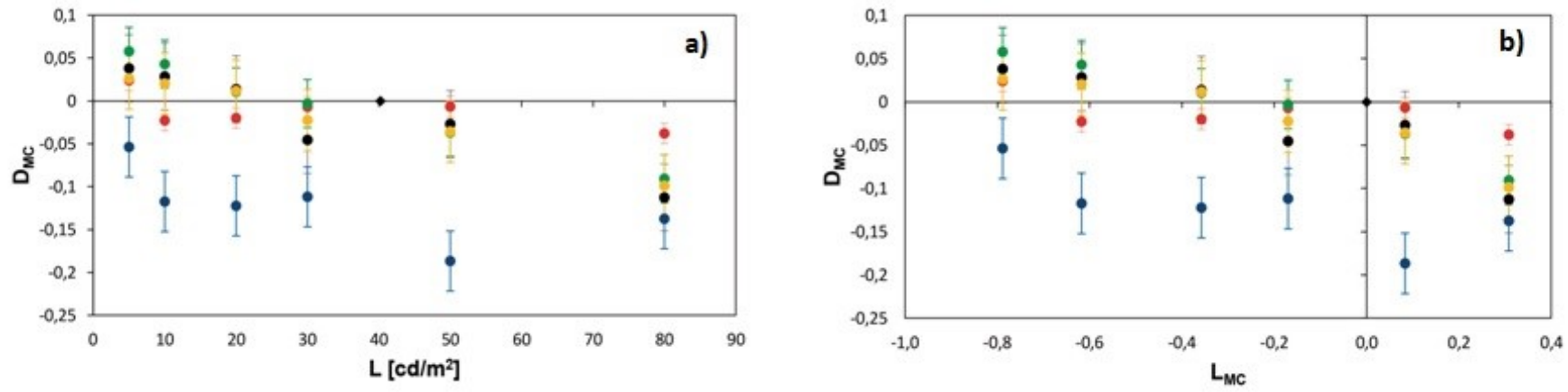

Figure 9. Michelson contrast pupillary diameter for all stimuli versus a) luminance and b) Michelson contrast luminance.

It is clear that in general the pupillary diameter has the tendency to decrease when the luminance increases. For the red stimuli, luminance seems to induce almost no impact on the pupil diameter, while the other stimuli do induce pupil dilatation (with respect to the reference stimulus) at low luminance and pupil contraction for the highest luminance values, except for the blue stimuli, which induce even at the lowest luminance a pupil contraction. In addition, for the 
luminance values that produce pupillary contraction for all hues, it is observed that the contraction is always higher for the blue stimuli.

\subsection{Pupillary diameter and brightness}

In Figure 10 the Michelson contrast pupillary diameter $D_{M C}$ is shown versus the Michelson contrast brightness $Q_{M C}$ for all stimuli.

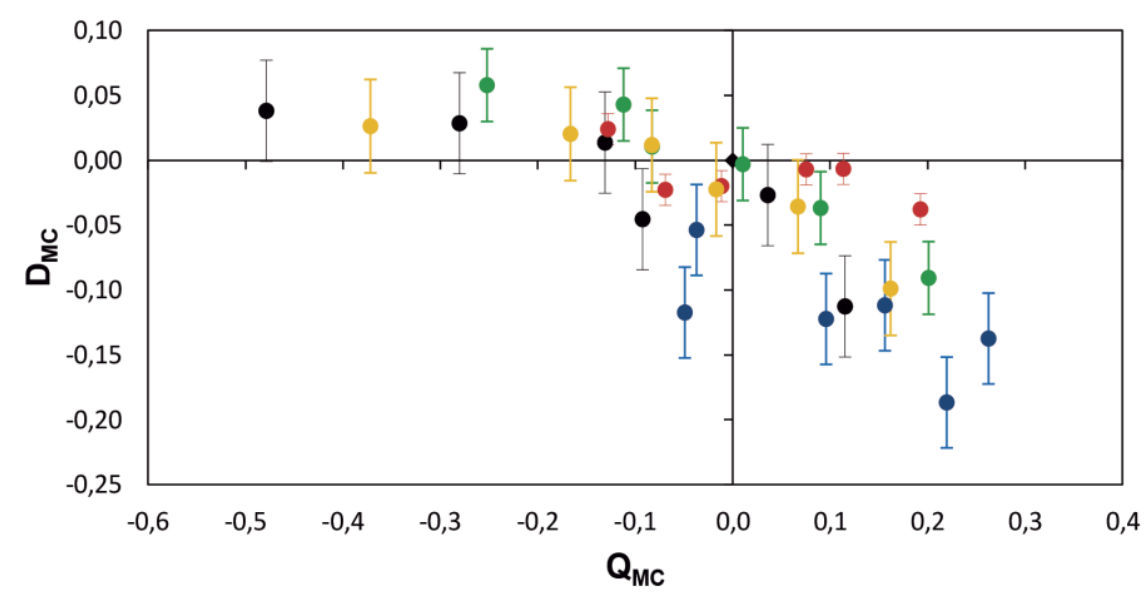

Figure 10. Michelson contrast pupillary diameter versus Michelson contrast brightness for all stimuli.

Figure 10 shows that in general the pupillary diameter decreases when the brightness increases (except for the red ones), and that for a given brightness the blue stimuli induce pupil contractions always higher than other hues.

It is observed that some stimuli (in particular the blue ones) that have less luminance than the reference and for which however the diameter contracts with respect to that of the reference (Fig 9), are perceived brighter than the reference (Fig 10 ). In these cases, pupillary diameter constriction (negative $D_{M C}$ ) is clearly related to positive $Q_{M C}$, according to the expected behavior. The relationship between pupillary diameter and the strength of the stimulus seems to be better represented when considering a psychophysical variable (brightness) instead of a photometric variable (luminance).

\subsection{Pupillary diameter, luminance and brightness}

The linear correlation between $L_{M C}$ and $Q_{M C}$ with $D_{M C}$ has been analyzed. The coefficient of determination $R^{2}$, Pearson correlation coefficient $r_{p}$ and Spearman rank correlation coefficient $r_{s}$ shown in table 5 were obtained.

\begin{tabular}{|l|c|c|c|}
\cline { 2 - 4 } \multicolumn{1}{c|}{} & $\boldsymbol{R}^{\mathbf{2}}$ & $\boldsymbol{r}_{\boldsymbol{P}}$ & $\boldsymbol{r}_{\boldsymbol{s}}$ \\
\hline$L_{M C}$ & 0.35 & -0.59 & -0.59 \\
\hline$Q_{M C}$ & 0.56 & -0.75 & -0.81 \\
\hline
\end{tabular}

Table 5. Coefficient of determination, Pearson correlation coefficient and Spearman rank correlation coefficient for $D_{M C}$ with $L_{M C}$ and $Q_{M C}$.

The values of $R^{2}$ show that the percentage of the variability of the data explained by the association between $D_{M C}$ and $Q_{M C}$ is greater than that between $D_{M C}$ and $L_{M C}$.

The values obtained for the Pearson correlation coefficient indicate that the intensity of the relationship between $D_{M C}$ and $Q_{M C}$ is greater than that of the relationship between $D_{M C}$ and $L_{M C}$.

The statistical significance of the difference in the two Pearson correlation coefficients was checked using the method for overlapping correlated correlation coefficients proposed by Meng et al. ${ }^{68}$. A significant difference $(p=0.03)$ could be detected between the correlations, indicating that $Q_{M C}\left(r_{p}=-0.75\right)$ was found to have a significantly better $(p=0.03)$ 
correlation with $D_{M C}$ than $L_{M C}\left(r_{p}=-0.59\right)$. However, from Fig. 9, it is clear that the "blue" stimuli deviate substantially from the rest of the stimuli. When the blue stimuli are removed, the Pearson correlation of $L_{M c}$ increases in absolute value to $r_{p}=-0.86$, but no significant difference could be detected with that of $Q_{M C}\left(r_{p}=-0.77\right)$, as the $p$-value for the difference was 0.09 .

Our results allow us to suggest that for all stimuli (including the blue ones) perceived brightness has a greater effect on pupillary diameter than luminance. However, the correlation is still not that high. Although red and blue stimuli generate both a high $Q_{M C}$ (due to the H-K effect), blue stimuli induce a far larger pupillary response than the red stimuli. This result is compatible with what is reported by Young \& Kimura in $2008^{6}$.

\subsection{Pupillary diameter and photoreceptors excitations}

In Figure 11, the Michelson contrast pupillary diameter $D_{M C}$ values are shown as a function of the Michelson contrast excitations $\rho_{M C}, \gamma_{M C}, b_{M C}$, rod ${ }_{M C}$ and $i p R G C_{M c}$. 

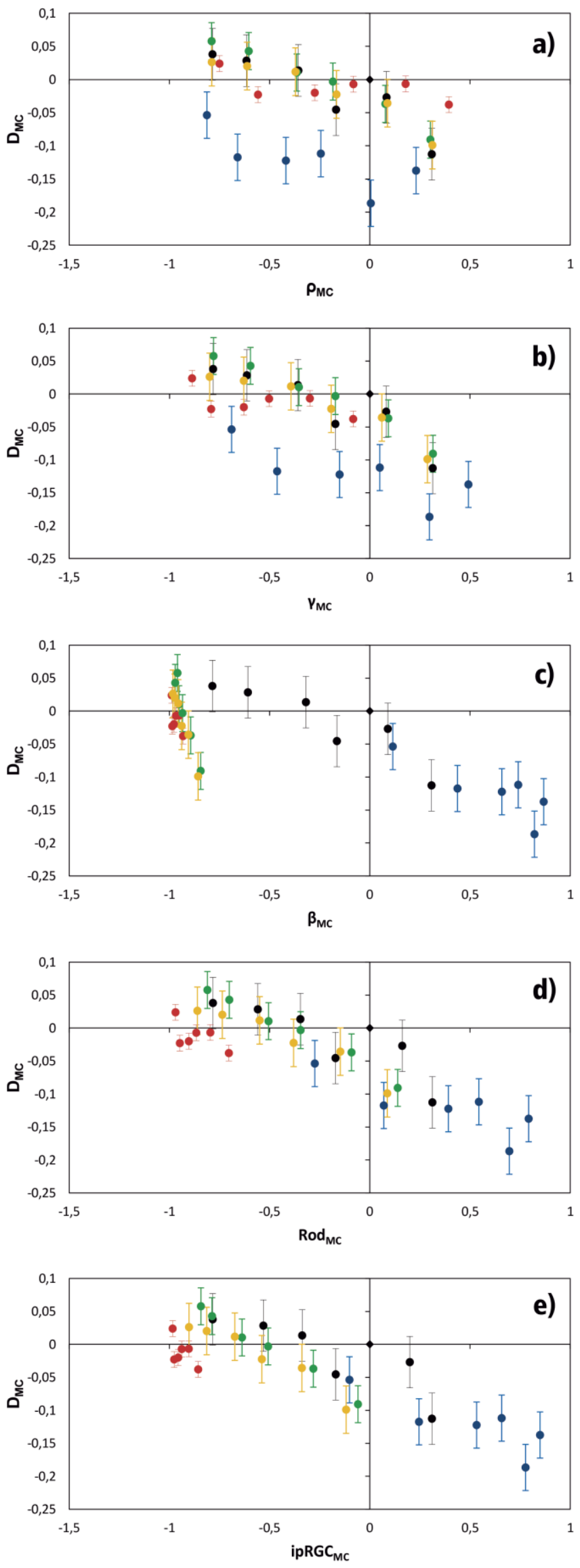

Figure 11. Michelson contrast pupillary diameter versus the Michelson contrast of the photoreceptors excitations: a) $\rho$ cones, b) $\gamma$ cones, c) $\beta$ cones, d) rods, e) ipRGCs. 
It can be noted that the general tendency is that the Michelson contrast pupillary diameter decreases when the Michelson contrast excitations of the photoreceptors increase. The particular influence of the excitation of each photoreceptor on pupillary size has not yet been separated in humans so as to identify their independent and combined contributions $^{69}$. Some authors find that the cones and ipRGCs influence the pupillary size together ${ }^{70}$. Other authors suggest that the selective activation of the cones $\rho, \gamma$ and $B$ does not necessarily produce the same effect (constriction or dilation) on pupillary size ${ }^{11,71}$. This topic is currently the subject of extensive and active research work in the scientific community.

When five linear models for $D_{M C}$ (versus $\rho_{M C}, \gamma_{M C}, B_{M C}, \operatorname{rod}_{M C}$ and $i p R G C_{M C}$, respectively) were adjusted, the coefficient of determination, Pearson correlation coefficient and Spearman rank correlation coefficient shown in Table 6 were obtained.

\begin{tabular}{|l|c|c|c|}
\cline { 2 - 4 } \multicolumn{1}{c|}{} & $\boldsymbol{R}^{\mathbf{2}}$ & $\boldsymbol{r} \boldsymbol{P}$ & $\boldsymbol{r}$ \\
\hline$\rho_{M C}$ & 0.25 & -0.50 & -0.55 \\
\hline$\gamma_{M C}$ & 0.52 & -0.72 & -0.70 \\
\hline$B_{M C}$ & 0.57 & -0.76 & -0.68 \\
\hline rod $d_{M C}$ & 0.72 & -0.85 & -0.75 \\
\hline ipRG $_{M C}$ & 0.72 & -0.85 & -0.71 \\
\hline
\end{tabular}

Table 6. Coefficient of determination, Pearson correlation coefficient and Spearman rank correlation coefficient for the variable $D_{M C}$ with Michelson contrast excitations of photoreceptor.

From the comparison of the values obtained for the Pearson coefficients, it is observed that the correlation of the pupillary diameter with the excitations of rods and ipRGCs is stronger than with the excitations of cones. The values obtained for $R^{2}$ show that the excitations of rods and ipRGCs explain in greater percentage the variability of the pupillary diameter than the excitations of cones. The similarity in the influence of rods and ipRGCs is of course related to the similarity of their spectral responses; however, it is worth emphasizing that these two photoreceptor responses have a higher correlation with pupil size than the cone responses.

It could be expected that under conditions of photopic lighting similar to those prevailing in this research, rods are inactive $^{72}$ and the ipRGC response is the major driving mechanism. Nevertheless, Zele et al. ${ }^{70}$ have found that rods, cones and ipRGC are complementary to the pupillary light reflex, since the rod-cone pathway does require ipRGCs for a functional pupillary response. Other recently obtained results show that for mice, rods take part in driving visual responses in daylight conditions ${ }^{73}$. Our results may be compatible with the hypothesis that this also occurs for humans.

\section{CONCLUSION}

The correlation between the initial pupillary reflex, the perceived brightness and the excitations of the photoreceptors was investigated for thirty unrelated self-luminous $10^{\circ}$ stimuli of 5 different hues (white, blue, red, green and yellow) and 6 luminance levels $\left(5,10,20,30,50\right.$ and $\left.80 \mathrm{~cd} / \mathrm{m}^{2}\right)$. Blue stimuli had the highest saturation, followed in decreasing order by red, green and yellow ones. Six observers with normal colour vision participated in this research. While the dependence of the pupillary diameter with luminance has been extensively investigated, the dependence of the pupillary diameter with brightness has been little studied so far. The incidence of photoreceptor excitations on pupillary diameter has been introduced due to their plausible relationship with brightness perception. The circular stimuli of $10^{\circ}$ were generated by illuminating a large diffuser from the rear by a projector. One equal-energy white stimulus of 42.3 $\mathrm{cd} / \mathrm{m}^{2}$ was used as reference and it was shown in between each test stimulus. All stimuli were optically characterized using a spectroradiometer. The background was always kept dark.

The pupillary diameter and the perceived brightness were measured for each observer, for all stimuli. Inter-observer variability for each stimulus and intra-observer variability for each observer were evaluated by calculating the STRESS values. For determining the pupillary diameter an Eye Tracker was used. The perceived brightness was evaluated with the magnitude estimation method. 
The variation of the pupillary size in time clearly shows pupillary contractions and pupillary dilatations as a response to changes of luminance and chromaticity from the reference to the test stimuli. In general, the pupil diameter data show large fluctuations which might be related with spontaneous pupillary oscillations and cognitive/emotional processes developed by the observer.

Most analytical models describing the pupil diameter use luminance as input. The correlation of the pupillary diameter with stimulus luminance has been investigated. Red stimuli seem to induce almost no impact on the pupillary diameter, while the other stimuli do induce pupillary dilatation at low luminance and pupil contraction for the highest luminance values, except for the blue stimuli, which induce even at the lowest luminance a pupil contraction. In addition, for the luminance values that produce pupillary contraction for all hues, it is observed that the contraction is always higher for the blue stimuli, in accordance with results obtained by other authors.

In addition to the measurement of pupil diameter, observers also made brightness estimations. The average perceived brightness was studied as a function of the stimuli luminance and saturation. As expected, brightness increased with luminance, and coloured stimuli having the same luminance as white stimuli were always observed brighter (HelmholtzKohlrausch effect). The perceived brightness values provided by the observers were compared with the CAM15u model predicted values and the correlation was quite well, supporting the validity of the model.

Pupillary diameter was studied as a function of the stimuli brightness. From the data, it can be concluded that the coefficient of determination between the pupillary diameter contrast and brightness contrast is higher than the value with luminance contrast. Even though the correlation is not that high, it seems that our results allow us to suggest that perceptual brightness has a greater effect on pupillary size than luminance.

Finally, pupillary diameter was studied as a function of the excitations of the five photoreceptors (rods, L-cones, Mcones, S-cones and ipRGCs). A general tendency to a pupillary diameter decrease when the photoreceptor excitation increases, is noted. Considering the spectral sensitivity of the photoreceptors, rods and ipRGCs excitations show a stronger correlation to the pupillary response than the excitation of cones. However, since photopic lighting conditions have been considered, it could be expected that under this condition rods are not very active and that the ipRGC response might be the major driving mechanism. Nevertheless, recently obtained results by other authors show that for mice even rods take part in driving visual responses in daylight conditions.

\section{APPENDIX: Instructions provided to observers}

At the beginning of each experimental session, the following instructions were provided to each observer:

"We are going to run the same sequence of 6 test stimuli of different hues twice.

In each sequence, first a reference stimulus will be shown for 20 seconds, then a test stimulus will be presented for 15 seconds, then the same reference stimulus will again be shown for 20 seconds, then another test stimulus will be presented for 15 seconds, and so on.

For each of these 6 stimuli, in the first run we will measure the diameter of your pupil and in the second run we will ask you about the brightness that you perceive.

In the first run, you will wear a frame of glasses that has a system to measure the pupillary diameter. You must keep your gaze fixed on the center of the circular stimuli. During this run, you will be able to know all the stimuli whose brightness you will have to evaluate later.

In the second run, the frame of glasses will be retired and you will be asked to give a value to the perceived brightness of the test stimulus with respect to that of the reference immediately after the test stimulus disappears. The reference is assigned a brightness value of 50. A value of zero represents a dark stimulus without any brightness. There is no upper limit to the value of brightness. A value of 50 represents a stimulus that seems to be just as bright as the reference, a value of 100 represents a stimulus appearing twice as bright as the reference, a value of 25 is given to a stimulus appearing half as bright, etc."

\section{FUNDING}


Argentinian authors would like to thank the Consejo Nacional de Investigaciones Científicas y Técnicas, CONICET, for supporting this research project (PIP0553). Belgian authors would like to thank the Research Council of the KU Leuven for supporting this research (C24/17/051). Author Smet would also like to thank the Research Foundation Flanders for the support through a postdoctoral fellowship (12B4916N). Finally, all authors want to thank the Research Foundation Flanders (FWO, BE) and MINCYT (AR) for the funding provided (VS.043.16N).

\section{REFERENCES}

1. Tsujimura S-i, Wolffsohn JS, Gilmartin B. Pupil Response to Color Signals in Cone-Contrast Space. Current Eye Research, 2006;31(5): 401-408. DOI:10.1080/02713680600681327.

2. Dunn FA, Lankheet MJ, Rieke F. Light adaptation in cone vision involves switching between receptor and postreceptor sites. Nature, 2007; 449:603-606.

3. Laeng B, Endestad T. Bright illusions reduce the eye's pupil. PNAS, 2012;109(6):2162-2167. DOI:10.1073/pnas.1118298109.

4. Hall CA, Chilcott RP. Eyeing up the Future of the Pupillary Light Reflex in Neurodiagnostics. Diagnostics, 2018; 8(19). Doi:10.3390/diagnostics8010019

5. Kimura E, Young RSL. Sustained pupillary constrictions mediated by an L- and M-cone opponent process. Vision Research, 2010;50:489-496. DOI:10.1016/j.visres.2010.01.001.

6. Young RSL, Kimura E. Pupillary correlates of light-evoked melanopsin activity in humans. Vision Res., 2008;48:862871.

7. Yellott J, Wandell B, Cornsweet T. The beginnings of visual perception: the retinal image and its initial encoding. Handbook of Physiology, Section 1: The Nervous System, Vol. III, Part 2. I. Darian-Smith, Ed., American Physiological Society Publisher; 1984.

8. Watson AB, Yellott JI. A unified formula for light-adapted pupil size. J. Vis., 2012;12(10),12:1-16, http://www.journalofvision.org/content/12/10/12

9. Kimura E, Young RSL. A chromatic-cancellation property of human pupillary responses. Vision Res., 1996;36,15431550.

10. McDougal DH, Gamlin PD. The influence of intrinsically-photosensitive retinal ganglion cells on the spectral sensitivity and response dynamics of the human pupillary light reflex. Vision Res., 2010;50: 72-87.

11. Woelders T, Leenheers T, Gordijn MCM, Hut RA, Beersma DGM, Wams EJ. Melanopsin- and L-cone-induced pupil constriction is inhibited by S- and M-cones in humans. Proceedings of National Academy of Sciences of the USA, 2018;115(4):792-797. DOI: 10.1073/pnas.1716281115.

12. Bonmati-Carrion MA, Hild K, Isherwood C, Sweeney SJ, Revell VL, Skene DJ, Rol MA, Madrid JA. Relationship between Human Pupillary Light Reflex and Circadian System Status. PLoS ONE, 2016;11(9):e0162476. https://doi.org/10.1371/journal.pone.0162476

13. Hattar S, Liao HW, Takao M, Berson DM, Yau KW. Melanopsin-containing retinal ganglion cells: architecture, projections, and intrinsic photosensitivity. Science, 2002;295:1065-1070.

14. Berson DM, Dunn FA, Takao M. Phototransduction by Retinal Ganglion Cells That Set the Circadian Clock. Science, 2002;295(5557):1070-1073. 
15. Gooley JJ, Ho Mien I, St. Hilaire MA, Yeo S-C, Chua EC-P, van Reen E, Hanley CJ, Hull JT, Czeisler CA, Lockley SW. Melanopsin and Rod-Cone Photoreceptors Play Different Roles in Mediating Pupillary Light Responses during Exposure to Continuous Light in Humans. J. Neurosci., 2012;32:14242-14253.

16. Gooley JJ, Lu J, Fischer D, Saper CB, Glickman G, Gerner E, Rollag M, Hull JT, Czeisler CA, Lockley SW. A broad role for melanopsin in nonvisual photoreception. J. Neurosci., 2003;23: 7093-106.

17. Dacey DM, Liao HW, Peterson BB, Robinson FR, Smith VC, Pokorny J, Yau KW, Gamlin PD. Melanopsin-expressing ganglion cells in primate retina signal colour and irradiance and project to the LGN. Nature, 2005;433:749-754.

18. Commission Internationale de l'Eclairage. International Lighting Vocabulary CIE. Eilv.cie.co.at/termlist.

19. Kardon R, Anderson SC, Damarjian TG, Grace EM, Stone E, Kawasaki A. Chromatic pupil responses: preferential activation of the melanopsin-mediated versus outer photoreceptor-mediated pupil light reflex. Ophthalmology, 2009;116(8):1564-73. DOI: 10.1016/j.ophtha.2009.02.007.

20. Villarreal-Calva E, Suaste-Gomez E. Metodología para cuantificar diferencias entre las respuestas pupilares evocadas por estímulos lumínicos cromáticos. Memorias Del Congreso Nacional De IngenieríA BioméDica, 2017;2(1): 402-406.

21. Fairchild MD. Color Appearance Models. 2nd ed. New York, John Wiley \& Sons; 2005.

22. Gamlin PDR, Zhang H, Harlow A, Barbur JL. Pupil responses to stimulus color, structure and light flux increments in the rhesus monkey. Vision Research, 1998;38(21): 3353-3358. doi:https://doi.org/10.1016/S0042-6989(98)00096-0

23. Atchison D, Smith G. Optics of the human eye. 3rd edition. Edinburgh, Elsevier; 2006.

24. Knapen T, de Gee JW, Brascamp J, Nuiten S, Hoppenbrouwers S, Theeuwes J. Cognitive and Ocular Factors Jointly Determine Pupil Responses under Equiluminance. PloS one, 2016;11(5), e0155574. https://doi.org/10.1371/journal.pone.0155574

25. Wang CA, Munoz DP. Neural basis of location-specific pupil luminance modulation. PNAS Proceedings of the National Academy of Science of the United States of America, 2018;115(41):10446-10451. https://doi.org/10.1073/pnas.1809668115

26. Zele AJ, Feigl B, Adhikari P, Maynard ML, Cao D. Melanopsin photoreception contributes to human visual detection, temporal and colour processing. Scientific Reports, 2018;8(1):3842. DOI: 10.1038/s41598-018-22197-w.

27. Hermans S, Smet KAG, Hanselaer P. Brightness Model for Neutral Self-Luminous Stimuli and Backgrounds. LEUKOS, 2018. DOI:10.1080/15502724.2018.1448280.

28. Withouck M, Smet KAG, Ryckaert WR, Pointer MR, Deconinck G, Koenderink J, Hanselaer P. Brightness perception of unrelated self-luminous colors. Journal of the Optical Society of America A, 2013;30(6).

29. Corney D, Haynes J-D, Rees G, Lotto RB. The Brightness of Colour. PLoS ONE, 2009;4(3):e5091.

https://doi.org/10.1371/journal.pone.0005091

30. Pridmore RW, Melgosa M. All Effects of Psychophysical Variables on Color Attributes: A Classification System. PLoS ONE, 2015;10(4):e0119024. https://doi.org/10.1371/journal.pone.0119024

31. Brown TM, Tsujimura S, Allen AE, Wynne J, Bedford R, Vickery G, Vugler A, Lucas RJ. Melanopsin-based brightness discrimination in mice and humans. Curr Biol., 2012;22(12):1134-41. DOI: 10.1016/j.cub.2012.04.039.

32. Lockhead GR. Psychophysical scaling: Judgments of attributes or objects? Behavioral and Brain Sciences, 1992;15:543-601. 
33. Nundy S, Purves D. A probabilistic explanation of brightness scaling. PNAS Proceedings of the National Academy of Science of the United States of America, 2002;99(22):14482-14487. https://doi.org/10.1073/pnas.172520399

34. Odgaard EC, Arieh Y, Marks LE. Cross-modal enhancement of perceived brightness: Sensory interaction versus response bias. Perception \& Psychophysics, 2003;65(1): 123-132

35. Donofrio R. Review Paper: The Helmholtz-Kohlrausch effect. Journal of the Society for Information Display, 2011;19. 10.1889/JSID19.10.658.

36. Brown TM, Tsujimura S, Allen AE, Wynne J, Bedford R, Vickery G, Vugler A, Lucas RJ. Melanopsin-Based Brightness Discrimination in Mice and Humans. Current Biology, 2012;22(12):1134-1141. https://doi.org/10.1016/j.cub.2012.04.039

37. Ware C. Lightness, Brightness, Contrast, and Constancy, in Information Visualization: Perception for Design. 3rd ed. Cambridge, Morgan Kaufman; 2013

38. Zele AJ, Adhikari P, Feigl B, Cao D. Cone and melanopsin contributions to human brightness estimation. JOSA A Journal of the Optical Society of America A, 2018;35(4): B19-B25. https://doi.org/10.1364/JOSAA.35.000B19

39. Commission Internationale de l'Eclairage. Publication CIE72, Colorimetry. Vienna; 2004.

40. Moskowitz HR. Magnitude estimation: Notes on what, how, when, and why to use it. Journal Food Quality, 1977;3:195.

41. Rich DC. Publication CIE 159: A colour appearance model for colour management systems, CIECAM02. Color Res Appl., 2006;31(2):158-158. DOI:10.1002/col.20198.

42. Withouck M, Smet KAG, Ryckaert WR, Hanselaer P. Experimental driven modelling of the color appearance of unrelated self-luminous stimuli: CAM15u. Opt Express, 2015;23(9):12045. DOI:10.1364/OE.23.012045.

43. Commission Internationale de l'Eclairage. Publication CIE15, Colorimetry. Vienna; 2004.

44. Arrington Research, Inc. ViewPoint EyeTracker PC-60 Software User Guide; 2004.

45. Young RSL, Kimura E, Delucia PR. A pupillometric correlate of scotopic visual acuity. Vision Research, 1995;35:22352241.

46. lacoviello $D$. Analysis of pupil fluctuations after a light stimulus by image processing and neural network. Computers and Mathematics with Applications, 2007;53:1260-1270.

47. Withouck M, Smet KAG, Ryckaert WR, Deconinck G, Hanselaer P. Predicting the brightness of unrelated selfluminous stimuli. Opt Express, 2014;22(13):16298. DOI:10.1364/OE.22.016298.

48. Stockman A, Sharpe LT. The spectral sensitivities of the middle- and long-wavelength-sensitive cones derived from measurements in observers of known genotype. Vision Res., 2000; 40:1711-1737.

49. Commission Internationale de l'Eclairage. CIE Proceedings, CIE Central Bureau, Paris 1; 1951.

50. Gamlin PDR, McDougal DH, Pokorny J, Smith VC, Yau KW, Dacey DM. Human and macaque pupil responses driven by melanopsin-containing retinal ganglion cells. Vision Res., 2007;47:946-954.

51. Guillon M, Dumbleton K, Theodoratos P, Gobbe M, Wooley CB, Moody K. The Effects of Age, Refractive Status, and Luminance on Pupil Size. Optometry and Vision Science, 2016;93(9):1093-100. DOI: 10.1097/OPX.0000000000000893. 
52. Cakmak HB, Cagil N, Simavli H, Duzen B, Simsek S. Refractive error may influence mesopic pupil size. Current Eye Research, 2010;35(2):130-6. DOI: 10.3109/02713680903447892.

53. Kukkonen H, Rovamo J, Tiippana K, Näsänen R. Michelson contrast, RMS contrast and energy of various spatial stimuli at threshold. Vision Research, 1993;33(10):1431-1436. https://doi.org/10.1016/0042-6989(93)90049-3.

54. Groß J. A normal distribution course. Peter Lang Publishing; 2004. ISBN 978-0820473482.

55. ASTM International. Standard test method for unipolar magnitude estimation of sensory attributes. West Conshohocken, PA: ASTM International; 2012: pp. 10. E1697-05:e1.

56. García PA, Huertas R, Melgosa M, Cui G. Measurement of the relationship between perceived and computed color differences. J Opt Soc Am A., 2007;24:1823-1829. DOI:10.1364/JOSAA.24.001823.

57. Kloosterman NA, Meindertsma T, van Loon AM, Lamme VAF, Bonneh YS, Donner TH. Pupil size tracks perceptual content and surprise. European Journal of Neuroscience, 2015; 1-11. doi:10.1111/ejn.12859

58. Joshi S, Li Y, Kalwani RM, Gold Jl. Relationships between Pupil Diameter and Neuronal Activity in the Locus Coeruleus, Colliculi, and Cingulate Cortex. Neuron, 2016;89(1):221-234. https://doi.org/10.1016/j.neuron.2015.11.028

59. Stanten SF, Stark L. A statistical analysis of pupil noise. IEEE Trans Biomed Eng., 1966;13:140-152.

60. Warga $M$, Lüdtke $H$, Wilhelm $H$, Wilhelm B. How do spontaneous pupillary oscillations in light relate to light intensity? Vision Res., 2009;49:295-300.

61. Loewenfeld IE. The pupil: anatomy, physiology, and clinical applications. Butterworth and Heinemann, Boston, MA.; 1999.

62. Bokoch MP, Behrends M, Neice A, Larson MD. Fentanyl, an agonist at the mu opioid receptor, depresses pupillary unrest. Auton Neurosci., 2015;189:68-74.

63. Kahneman D, Beatty J. Pupil diameter and load on memory. Science, 1966;154(3756):1583-5.

64. Kahneman D, Tursky B, Shapiro D, Crider A. Pupillary, heart rate, and skin resistance changes during a mental task. Journal of Experimental Psychology, 1969;79(1, Pt.1):164-167.

65. Partala T, Surakka V. Pupil size variation as an indication of affective processing. International Journal of HumanComputer Studies, 2003;59(1-2):185-198. Doi: 10.1016/S1071-5819(03)00017-X

66. Henderson RR, Bradley MM, Lang PJ. Emotional imagery and pupil diameter. Psychophysiology, 2017;e13050. https://doi.org/10.1111/psyp.13050

67. Melgosa M, García PA, Gómez-Robledo L, Shamey R, Hinks D, Cui G, Luo MR. Notes on the application of the standardized residual sum of squares index for the assessment of intra- and inter-observer variability in color-difference experiments. J. Opt. Soc. Am. A, 2011;28(5).

68. Meng XL, Rosenthal R, Rubin DB. Comparing correlated correlation coefficients. Psychol Bull, 1992;111:172-175.

69. Zele AJ, Adhikari P, Cao D, Feigl B. Melanopsin and Cone Photoreceptor Inputs to the Afferent Pupil Light Response. Front. Neurol., 2019;10:529. DOI: 10.3389/fneur.2019.00529

70. Rao F, Chan AHS, Zhu XF. Effects of photopic and cirtopic illumination on steady state pupil sizes. Vision Research, 2017;137:24-28. DOI: 10.1016/j.visres.2017.02.010. 
71. Spitschan M, Jain S, Brainard DH, Aguirre GK. Opponent melanopsin and S-cone signals in the human pupillary light response. PNAS, Proceedings of the National Academy of Sciences, 2014;111(43):15568-15572. www.pnas.org/cgi/doi/10.1073/pnas.1400942111

72. Stockman A, Sharpe LT. Into the twilight zone: the complexities of mesopic vision and luminous efficiency. Ophthalmic and Physiological Optics, 2006;26(3):225-39.

73. Tikidji-Hamburyan A, Reinhard K, Storchi R, Dietter J, Seitter H, Davis KE, Idrees S, Mutter M, Walmsley L, Bedford RA, Ueffing M, Ala-Laurila P, Brown TM, Lucas RJ, Münch TA. Rods progressively escape saturation to drive visual responses in daylight conditions. Nature Communications, 2017;8(1):1813. DOI: 10.1038/s41467-017-01816-6.

\section{AUTHOR BIOS}

Claudia Sandoval Salinas is a PhD student in the Department of Lighting, Light and Vision at the Argentina National University of Tucumán, Argentina. She is a physicist and a physics teacher. The main goal of her PhD research is to create a colour appearance model for light sources of related colours that incorporates the influence of the pupil size of the observer.

Stijn Hermans is a PhD student at the Light\&Lighting Laboratory, Ghent, BELGIUM. He has a master's degree in physics and astronomy and is nowadays active in modelling the colour perception of light sources. The main goal of his PhD research is to create a colour appearance model for light sources seen in relation to each other.

José Sandoval is an Electrical Engineer. He has a master degree in Lighting and he is an Associate Professor (Radiometry and Photometry; Colorimetry) at the National University of Tucuman (UNT-Tucumán-Argentina). His main research areas are perception of light and colour, measurement of light and colour, light and museum environment, lighting for exhibition and preservation of cultural heritage, digitization of works of art and the impact of colour in the exhibition of artistic paintings.

Kevin A.G. Smet obtained his PhD in Engineering at KU Leuven in 2011. He is currently appointed as an Associate Research Professor at KU Leuven. He is the team leader of the Appearance \& Perception group of the Ligh\&Lighting Laboratory and is an active member of CIE Division 1. His research interests include color rendition and color quality of white light sources, color appearance modeling, memory and preferred colors, perception of light and color in virtual reality and color science in general.

Peter Hanselaer holds a PhD in solid state physics and is a Full Professor at KU Leuven (BE). In 1997, he founded the Light \& Lighting Laboratory. His main research areas are lighting, perception and appearance, optical design, light sources, and optical metrology. He is the Editor of CIE Division 1 and Chair of the Advisory Committee of the Faculty of Engineering Technology of KU Leuven. He is teaching master courses in photonics, optical fibers and lighting.

Elisa Colombo holds a PhD in light and vision from the National University of Tucuman (UNT, Argentina). She is a Full Titular Professor at UNT and a Principal Research at CONICET (National Council for Scientific and Technical Research, Argentina). Her main research areas are functional vision and lighting, visual optic and early vision. She teaches courses about these subjects for lighting designers and for master and PhD postgraduate students. 